\title{
Compensation of Voltage Unbalance and Current Harmonics with a Series Active Power Filter
}

\author{
Salvador P. Litrán, Patricio Salmerón, Jesús R. Vázquez and Juan L. Flores \\ Department of Electrical Engineering \\ Escuela Politécnica Superior, Universidad de Huelva \\ Ctra. de Palos de la Frontera s/n 21819, Palos de la Frontera. Huelva (Spain) \\ phone:+34 959 017585, fax:+34 959017304 \\ e-mail salvador@uhu.es, patricio@uhu.es, vazquez@uhu.es, jlflores@uhu.es
}

\begin{abstract}
A combined system of shunt passive and series active filter for a four-wire three-phase system has been designed and simulated with Matlab/Simulink. The system combined mitigates the source current harmonics and compensates also unbalance voltages reducing the problems of using only a shunt passive filter. Therefore, a new control method based in the power vectorial theory has been proposed. The compensation principle is presented in detail. To verify the effectiveness of the proposed control, simulation results are presented and discussed.
\end{abstract}

\section{Key words}

Active filters, passive filter, harmonic suppression, voltage unbalance.

\section{Introduction}

Traditionally, nonlinear loads have been modelled as current sources because their waveforms are distorted from pure sine-waveforms at fundamental frequency and the harmonic current contents and characteristics are less dependent of the system voltage. Although other solutions have been proposed [1], shunt passive filters and shunt active filters are commonly applied to these loads to suppress harmonics and to improve the power factor in power systems.

so that

The shunt passive filter consists of some LC branches that are connected in parallel with the load. Its function is based on providing, at a tuned harmonic frequency, a lower impedance than the one of the source in order to reduce the harmonic currents flowing into the source. However shunt passive filters have the following problems, that may discourage the engineers from their application:

a. The filtering characteristics are strongly influenced by the source impedance, which is usually not well known and depends on the system configuration. b. The passive filter works as a sink for the harmonics generated elsewhere on the ac system, including harmonics of the ac source. This fact makes it difficult to design the LC filters.

c. At a determined frequency, there is always a series resonance between source impedance and passive filter. For the circuit showed in figure 1, this frequency corresponds to that of the equation (1).

$$
f_{0}=\frac{1}{2 \pi \sqrt{\left(L_{S}+L_{F}\right) C_{F}}}
$$

where $\mathrm{L}_{\mathrm{S}}$ is the source inductance, and $\mathrm{L}_{\mathrm{F}}$ and $\mathrm{C}_{\mathrm{F}}$ are the inductance and capacitance of the $\mathrm{LC}$ branch.

d. This kind of filter cannot solve random variations in the load current waveform.

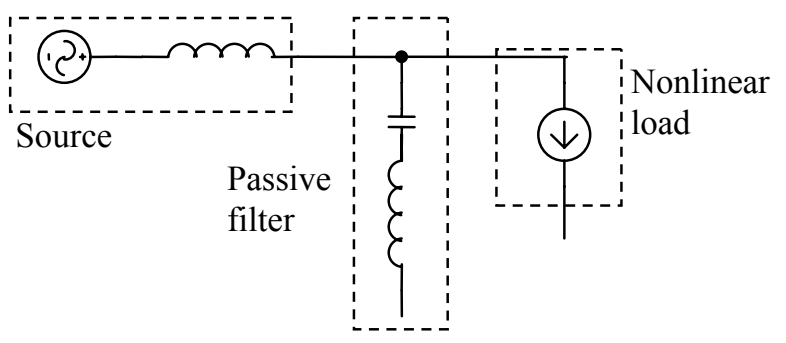

Fig. 1. Basic principle of shunt passive filter

To solve the problems of the passive filters, parallel active filters using a PWM converter have been developed. The operation principle of the active power filter is to inject into the line the harmonic current consumed by the load, so that the source current becomes a pure sinusoidal waveform. They have good compensation characteristics, but they also have the following problems in terms of their practical applications:

a. It is difficult to build a large rated current source with a fast current response.

b. Initial cost and running cost are high. 


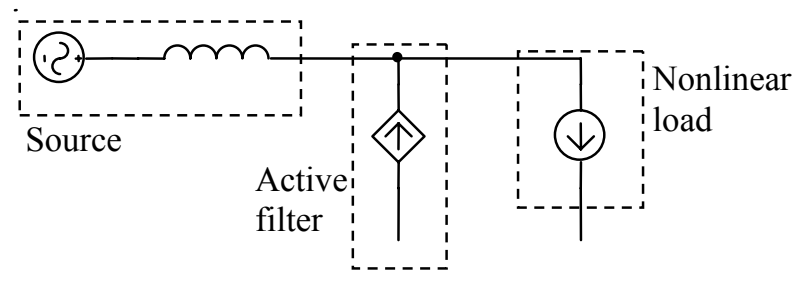

Fig. 2. Basic principle of a shunt active filter

Some solutions have been proposed to improve the performance of passive LC filters and to eliminate the problems of the shunt active filter. One of them is the use of a combined system of shunt passive filter and a series active filter [2-6]. In a first approach the shunt passive filter connected in parallel with a load suppresses the prevalent harmonics currents produced by the load, while the active filter connected in series with a source acts as a "harmonic isolator" between the source and the load. The active filter improves the filtering characteristics of the passive filter and can cover another aspects as voltage restoring [7,8]. Therefore, the PWM inverter is smaller $\mathrm{VA}$ rating than in the other configurations.

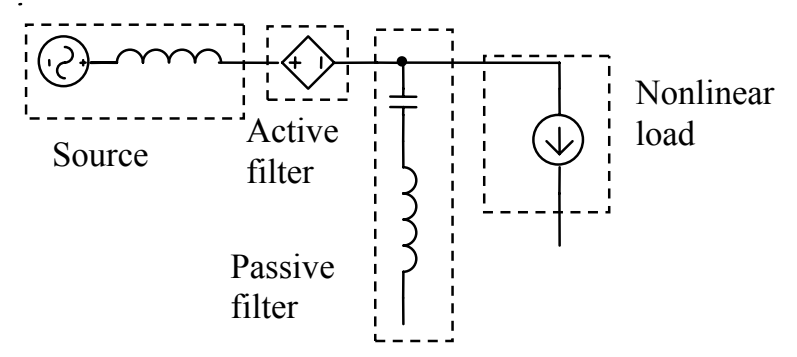

Fig. 3. Basic principle of a combined system

In this paper a new control system based on the vectorial theory of the electric power [9] is applied to a combined system, which enables to improve the compensation characteristics of a passive filter and also enables to compensate the negative and zero sequence components of voltages by a three-phase four-wire system. The complete system has been designed and simulated with Matlab/Simulink software.

\section{Operation principles}

In the system of figure 3 , the purpose is to simultaneously compensate voltages unbalances and current harmonic components at the load terminals.

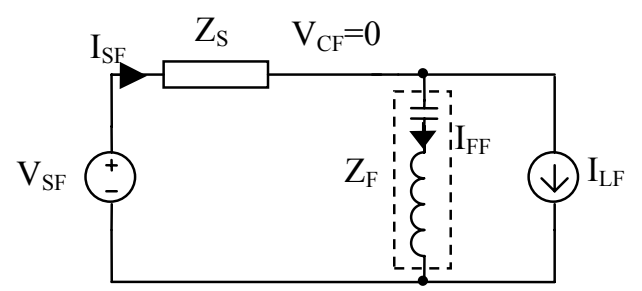

Fig.4. Equivalent circuit for fundamental frequencies
In order to avoid the presence of harmonics at the source current, the active filter is controlled to present zero impedance at the fundamental frequency and a high impedance at the frequencies of the load harmonics. Figure 4 shows the single phase equivalent circuit for fundamental harmonic, and fig. 5 for the rest of harmonics, where to simplify, the active filter is considered as an ideal controllable voltage source. The nonlinear load is represented by a current source $\mathrm{I}_{\mathrm{L}}$, the impedance of the passive filter is $Z_{F}$, and $Z_{S}$ is the source impedance.

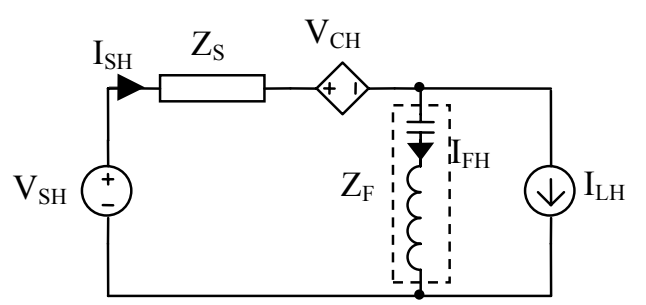

Fig. 5. Equivalent circuit for harmonic frequencies

The following equation is given for the circuit of the fig. 5

$$
\left(Z_{S}+Z_{F}\right) I_{S H}=Z_{F} I_{L H}+V_{S H}-V_{C H}
$$

To achieve high impedance at the frequencies of the load harmonics, the output voltage of the series active filter must be proportional to the source current harmonics, that is,

$$
V_{C H}=K I_{S H}
$$

So the harmonic current flowing at the source side is given by

$$
I_{S H}=\frac{Z_{F}}{\left(Z_{S}+Z_{F}+k\right)} I_{L H}+\frac{1}{\left(Z_{S}+Z_{F}+k\right)} V_{S H}
$$

When $\mathrm{K}>>\mathrm{Z}_{\mathrm{S}}, \mathrm{Z}_{\mathrm{F}}$, then $\mathrm{I}_{\mathrm{SH}} \approx 0$

The compensation characteristic becomes ideal when the active filter presents an infinite impedance, $K=\infty$. In this way the passive filter problems, namely, the parallel resonance and the harmonic sink, are solved.

Moreover, if the three-phase system is unbalanced, the active filter must eliminate the negative and zero sequence components of the load voltages, it is achieved generating the appropriate voltage waveforms with the inverter. These components are obtained applying the Fortescue transformation, defined by the following expression

$$
\left(\begin{array}{l}
v_{a 0} \\
v_{a 1} \\
v_{a 2}
\end{array}\right)=\frac{1}{\sqrt{3}}\left(\begin{array}{ccc}
1 & 1 & 1 \\
1 & a & a^{2} \\
1 & a^{2} & a
\end{array}\right)\left(\begin{array}{l}
v_{a} \\
v_{b} \\
v_{c}
\end{array}\right)
$$

Where $\mathrm{v}_{\mathrm{a}}, \mathrm{v}_{\mathrm{b}}$ and $\mathrm{v}_{\mathrm{c}}$ correspond to the phase to neutral voltages before active filter. 


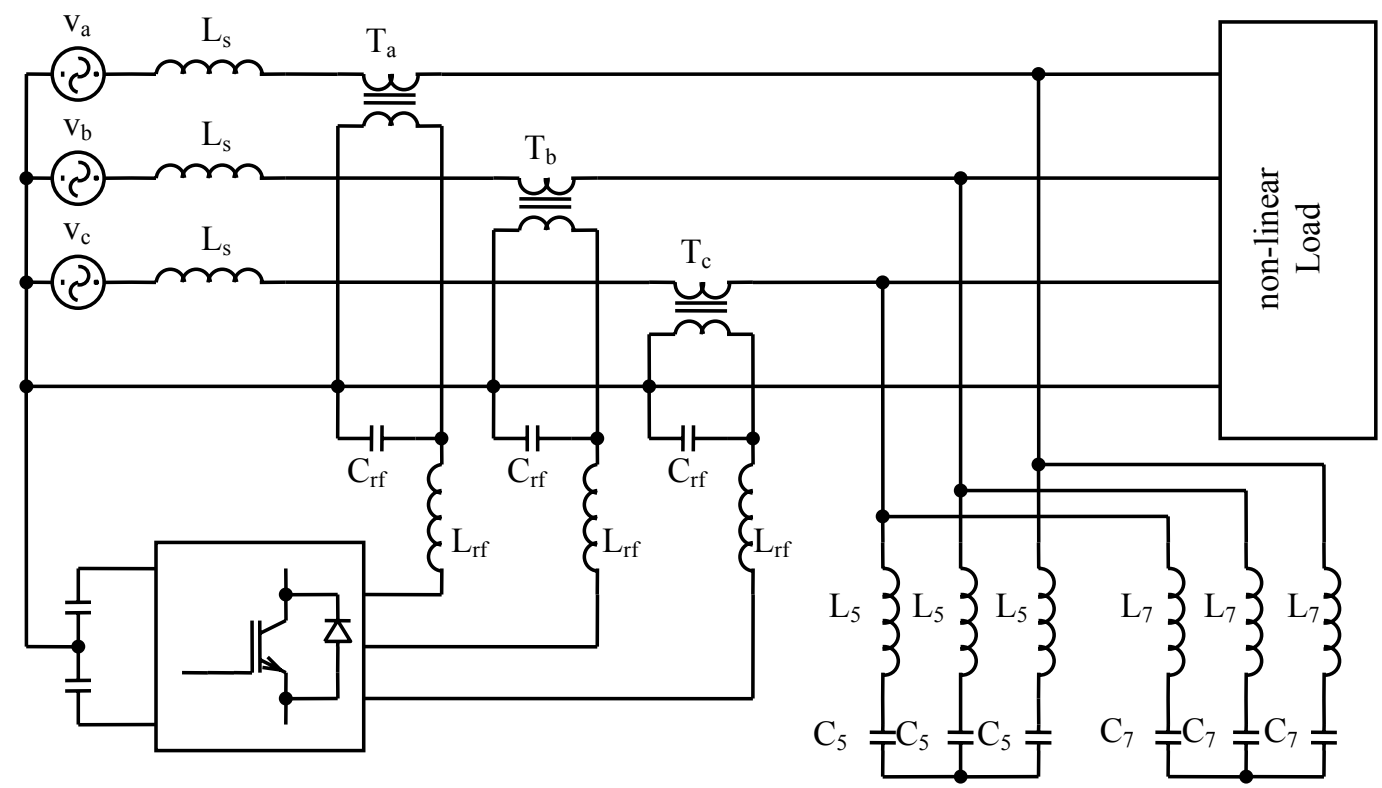

Fig. 6. Series active power filter topology.

\section{System configuration and control scheme}

Figure 6 shows a three-phase four-wire system with a nonlinear load. The source voltages can be unbalanced. The active power filter designed consists of a three-phase PWM voltage source inverter, which is connected in series with the ac source impedance and load, through three single phase transformers. Between the transformers and the inverter it is connected a small rate passive filter to suppress switching ripples.

A passive LC filter connected in parallel with the load is tuned to eliminate the fifth and seventh harmonics. For the fundamental harmonic, the passive filter also must supply the reactive power of the load.
The active filter must generate a voltage proportional to the harmonic component of the source current, which is calculated applying the vectorial theory of the electric power. The reference current is calculated as follows

$$
\mathbf{i}_{\text {ref }}=\mathbf{i}_{\mathbf{L}}-\frac{\mathrm{P}}{v^{2}} \mathbf{v}
$$

Where

$\mathbf{i}_{\mathrm{L}}$ : current vector of the load and passive filter.

P: average power defined by $\mathrm{P}=\frac{1}{\mathrm{~T}} \int_{0^{\prime}}^{T}\left(\mathbf{u}^{\mathrm{T}} \cdot \mathbf{i}\right) d t$

u: voltage vector before active filter.

$\mathbf{v}$ : voltage vector of direct sequence.

$v^{2}:$ norm of $\mathbf{v}$, defined by $v^{2}=\frac{1}{\mathrm{~T}} \int_{0^{\prime}}^{T}\left(\mathbf{v}^{\mathrm{T}} \cdot \mathbf{v}\right) d t$.

$\mathrm{T}$ is the fundamental period and "." denotes the dot product of vectors.

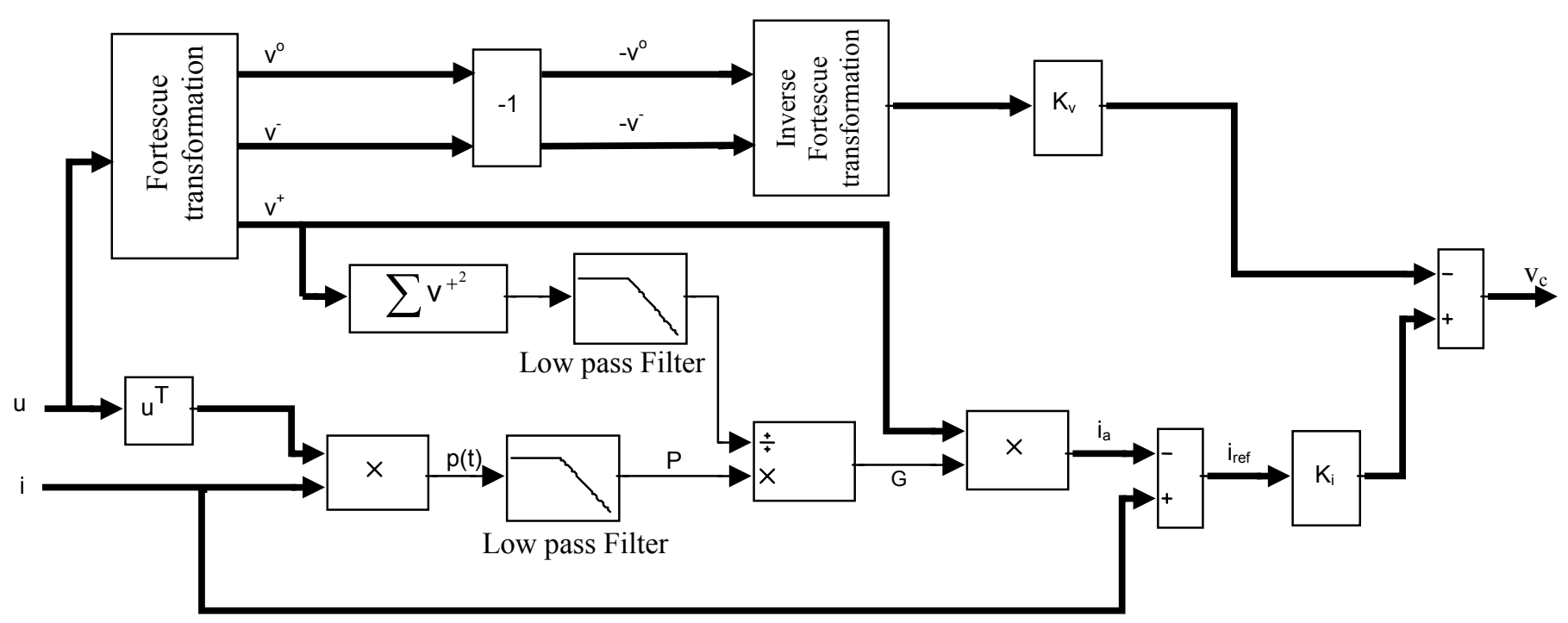

Fig. 7. Blocks diagram of the control scheme. 
The reference voltage to compensate the voltages unbalance is obtained by calculating the zero and inverse sequence components from equation (5). The active filter must generate this components, but in reverse phase. Applying the inverse of the Fortescue transformation, the following equations are obtained,

$$
\left(\begin{array}{c}
v_{r e f a} \\
v_{r e f b} \\
v_{r e f c}
\end{array}\right)=\frac{1}{\sqrt{3}}\left(\begin{array}{ccc}
1 & 1 & 1 \\
1 & a^{2} & a \\
1 & a & a^{2}
\end{array}\right)\left(\begin{array}{c}
-v_{a 0} \\
0 \\
-v_{a 2}
\end{array}\right)
$$

Where $v_{a 0}$ is the zero sequence component and $v_{a 2}$ the negative sequence component.

Figure 7 shows the control scheme for obtaining the reference signal. This signal is generated by the PWM inverter. The gain $\mathrm{K}_{\mathrm{V}}$ is the turn ratio of the series transformers, which is applied to the reference signals for the voltage unbalance. The gain $\mathrm{K}_{\mathrm{i}}$ is the proportional constant for the harmonics of the source current, it gets the magnitude of the impedance for high frequency. Thus, the inverter must generate the following waveform

$$
\mathbf{v}_{\mathbf{c}}=\mathrm{K}_{\mathrm{i}} \mathbf{i}_{\text {ref }}+\mathrm{K}_{\mathrm{v}} \mathbf{v}_{\text {ref }}
$$

The gating signals of the inverter are generated by comparing the resultant reference signal with the output of the inverter through a bang-bang control.

\section{Simulation results}

The performance of the proposed series active power filter has been verified by simulation using Matlab/Simulink software. The simulated circuit is shown in fig. 6, where the three phase voltage system is sinusoidal and unbalance. The source voltage rms values are: $\mathrm{V}_{\mathrm{a}}=220 \mathrm{~V}, \mathrm{~V}_{\mathrm{b}}=200 \mathrm{~V}$ and $\mathrm{Vc}=150 \mathrm{~V}$. Figure 7 shows this source voltage system.

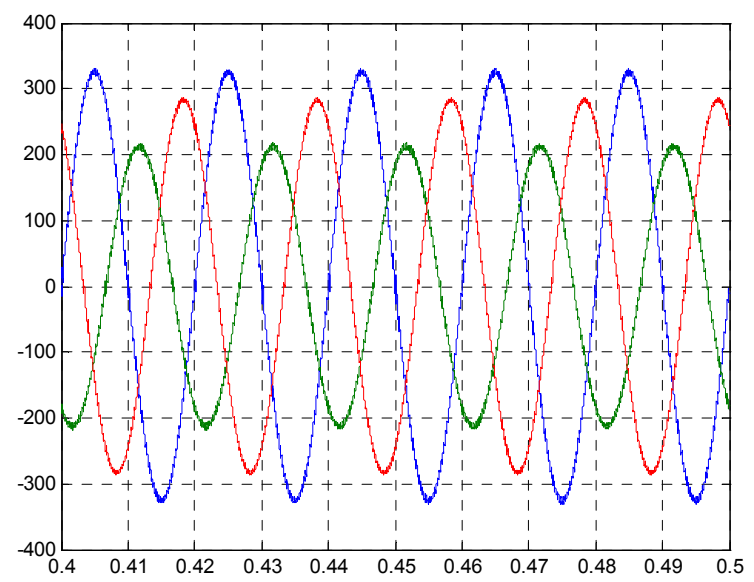

Fig. 7. Source voltage.
The parameters values of the passive elements are included in Table I.

TABLE I.- Passive elements parameters

\begin{tabular}{|l|c|c|}
\hline Source & \multicolumn{2}{|c|}{$\mathrm{Ls}=1 \mathrm{mH}$} \\
\hline Passive filter & $\mathrm{L}_{5}=6.22 \mathrm{mH}$ & $\mathrm{C}_{5}=65 \mu \mathrm{F}$ \\
\cline { 2 - 3 } & $\mathrm{L}_{7}=3.17 \mathrm{mH}$ & $\mathrm{C}_{7}=65 \mu \mathrm{F}$ \\
\hline Ripple filter & $\mathrm{L}=1.49 \mathrm{mH}$ & $\mathrm{C}=32 \mu \mathrm{F}$ \\
\hline
\end{tabular}

As the PWM inverter it was chosen the IGBT bridge model of System Power Blockset. For the connection of the inverter to the system three single transformers are used. At dc side there are two sources of $50 \mathrm{~V}$ connected.

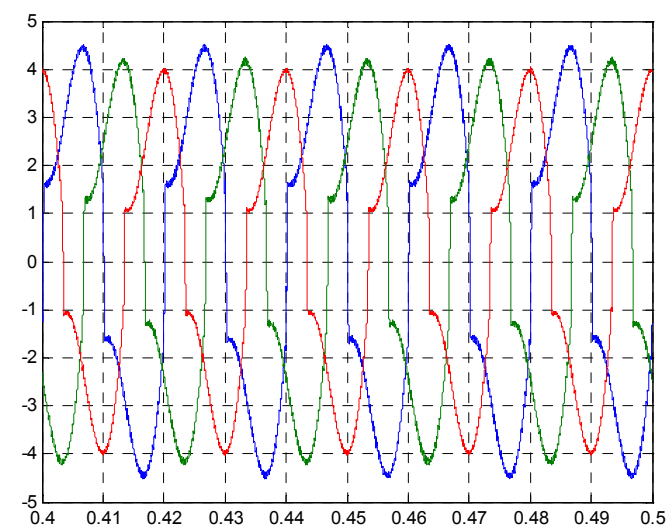

Fig. 8. Load current.

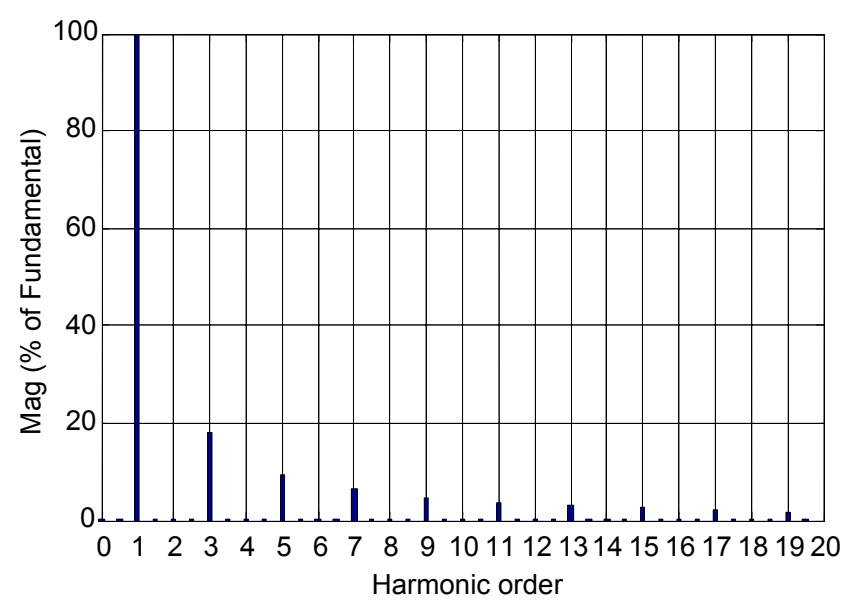

Fig. 9. Frequency spectrum of load current (phase 1)

The nonlinear loads are three single phase non-controlled rectifiers, each of them connected between phase and neutral. Figure 8 shows the load current when the system is not compensated. This current is clearly non-linear, containing odd order harmonics and a THD of $22.59 \%$. The frequency spectrum is shown in figure 9 and the table II presents the harmonic value in \% with respect to the fundamental component. 
TABLE II. - Harmonics values of the load current (phase 1)

\begin{tabular}{|l|l|l|l|}
\hline \multicolumn{4}{|c|}{$\begin{array}{l}\text { Fundamental }(50 \mathrm{~Hz})=4.408 \\
\text { THD }=22.59 \%\end{array}$} \\
\hline $\begin{array}{l}\text { Harmonic } \\
\text { order }\end{array}$ & $\%$ & $\begin{array}{l}\text { Harmonic } \\
\text { order }\end{array}$ & $\%$ \\
\hline 1 & 100 & 11 & 3.76 \\
\hline 2 & 0.03 & 12 & 0.01 \\
\hline 3 & 17.93 & 13 & 3.08 \\
\hline 4 & 0.01 & 14 & 0.00 \\
\hline 5 & 9.37 & 15 & 2.56 \\
\hline 6 & 0.01 & 16 & 0.01 \\
\hline 7 & 6.34 & 17 & 2.20 \\
\hline 8 & 0.00 & 18 & 0.01 \\
\hline 9 & 4.75 & 19 & 1.87 \\
\hline 10 & 0.01 & 20 & 0.00 \\
\hline
\end{tabular}

Figure 10 shows the source current when the passive filter is connected alone. The fifth and the seventh harmonics are eliminated of the source current, as can be seen at its frequency spectrum, which is shown in figure 11 and in table III (in \% of fundamental harmonic). The THD fall into $19.74 \%$. Besides it can be seen that the voltage unbalance can not be compensated with the passive filter.

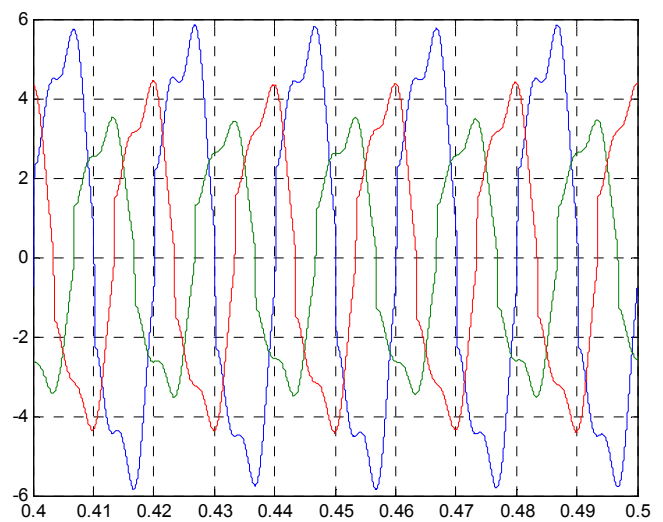

Fig. 10. Source current when pasive LC filter is connected

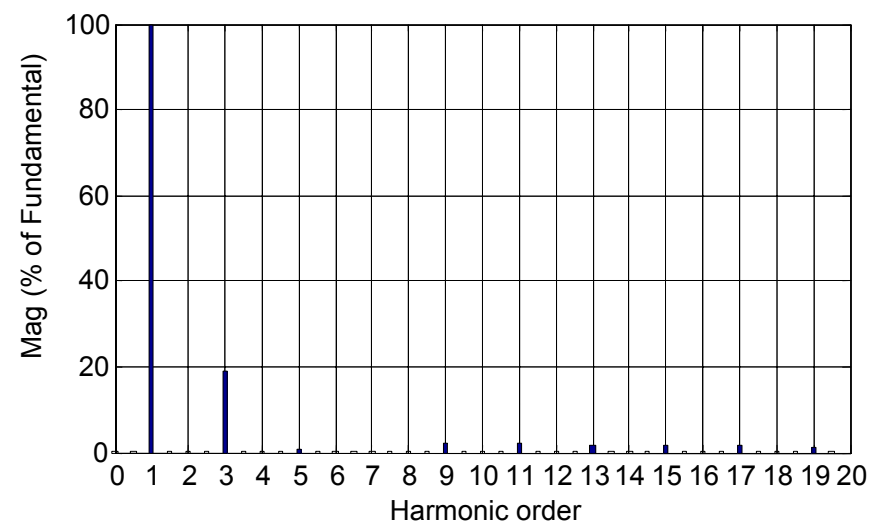

Fig. 11. Frequency spectrum of the source current (phase 1) when the passive $\mathrm{LC}$ filter is connected.
TABLE III. -Harmonics value of the source current (phase 1) when the passive LC filter is connected.

\begin{tabular}{|l|l|l|l|}
\hline \multicolumn{4}{|c|}{ Fundamental $(50 \mathrm{~Hz})=5.806$} \\
\hline $\begin{array}{l}\text { THD }=19.74 \% \\
\text { order }\end{array}$ & $\%$ & $\begin{array}{l}\text { Harmonic } \\
\text { order }\end{array}$ & $\%$ \\
\hline 1 & 100 & 11 & 2.15 \\
\hline 2 & 0.02 & 12 & 0.00 \\
\hline 3 & 19.21 & 13 & 1.91 \\
\hline 4 & 0.05 & 14 & 0.00 \\
\hline 5 & 0.64 & 15 & 1.69 \\
\hline 6 & 0.00 & 16 & 0.00 \\
\hline 7 & 0.30 & 17 & 1.50 \\
\hline 8 & 0.01 & 18 & 0.00 \\
\hline 9 & 2.27 & 19 & 1.35 \\
\hline 10 & 0.01 & 20 & 0.00 \\
\hline
\end{tabular}

When the series active power filter is connected, it is possible to obtain a balanced load voltage. The active filter generates the zero and inverse component of the voltage. As a result the voltages in the load are balanced, as show in figure 12

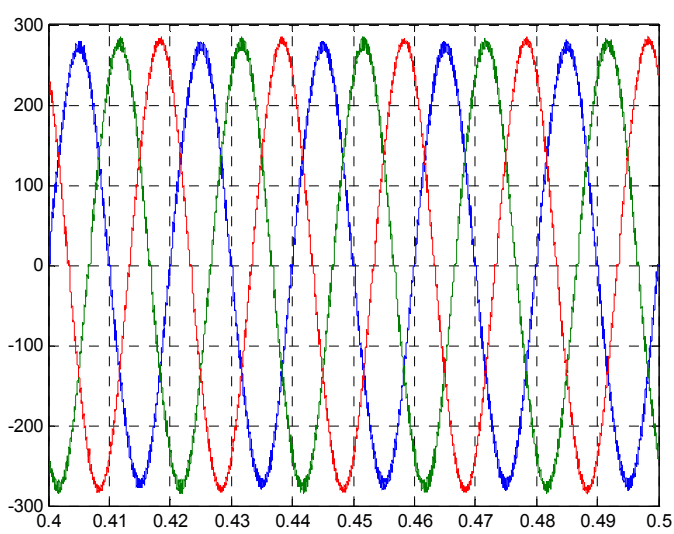

Fig. 12. Load voltage with series active power filter.

On other hand, the active filter improves the harmonics contents of the source currents. The circuit has been simulated with $\mathrm{k}_{\mathrm{i}}=1.5$. It is possible to improve the current waveform if the gain is higher but it deteriorates the applied voltage. Figure 13 shows the sources current obtained.

The frequency spectrum of the source current is shown in figure 14 and in table IV which is expressed in \% of harmonic fundamental. We can see how the harmonics values decrease, improving the THD from 19.74 to 4.41 $\%$. Other important fact is that the magnitude of the third harmonics decrease and as result the neutral wire current also decreases. 


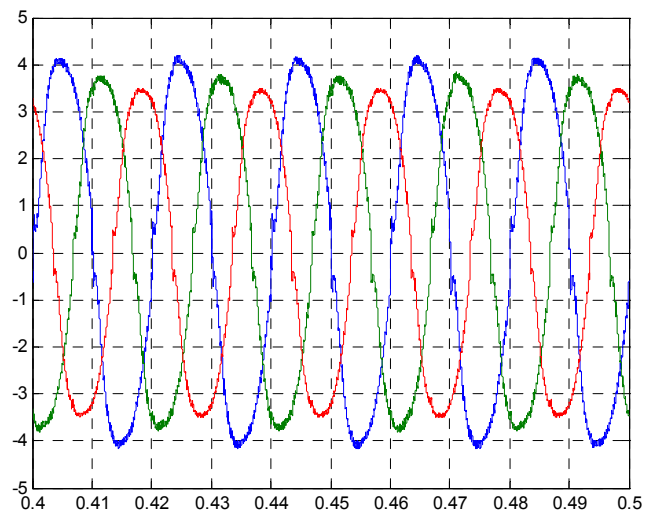

Fig. 13. Source current with series active power filter

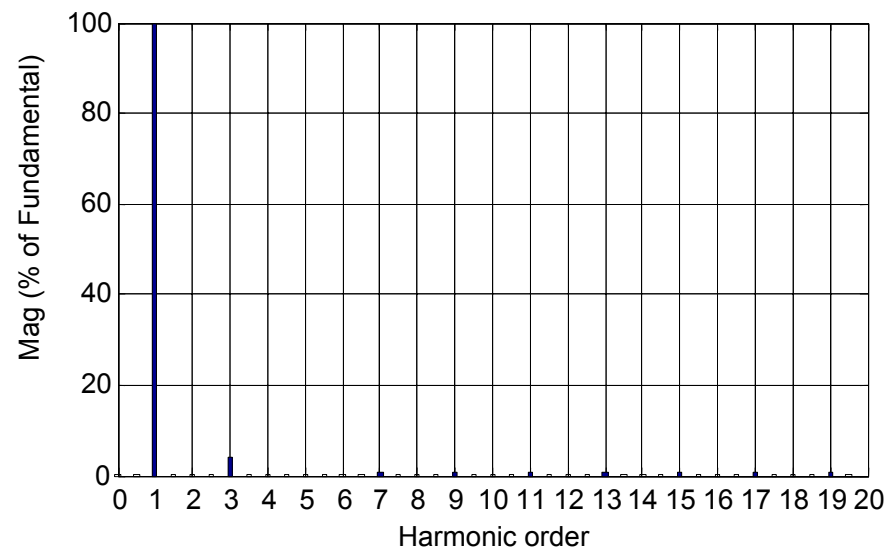

Fig 14. Frequency spectrum of the source current (phase 1) when the series active power filter is connected.

TABLE IV. Harmonics values of the source current (phase 1) when the series active power filter is connected.

\begin{tabular}{|c|c|c|c|}
\hline \multicolumn{4}{|c|}{ Fundamental $(50 \mathrm{~Hz})=4.298$} \\
\hline $\begin{array}{c}\text { Harmonic } \\
\text { order }\end{array}$ & $\%$ & $\begin{array}{c}\text { Harmonic } \\
\text { order }\end{array}$ & $\%$ \\
\hline 1 & 100 & 11 & 0.81 \\
\hline 2 & 0.09 & 12 & 0.13 \\
\hline 3 & 4.28 & 13 & 0.76 \\
\hline 4 & 0.21 & 14 & 0.04 \\
\hline 5 & 0.05 & 15 & 0.80 \\
\hline 6 & 0.00 & 16 & 0.09 \\
\hline 7 & 0.56 & 17 & 0.65 \\
\hline 8 & 0.05 & 18 & 0.05 \\
\hline 9 & 0.85 & 19 & 0.60 \\
\hline 10 & 0.13 & 20 & 0.00 \\
\hline
\end{tabular}

\section{Conclusions}

A combined system of shunt passive and series active filter for a four-wire three-phase system has been designed and simulated with Matlab/Simulink. A new control method based in the power vectorial theory has been proposed.

The proposed filter system has the following features:
- Decrease the harmonics component of the source currents, improving the THD.

- The magnitude of the third current harmonics decrease, and as result, decrease the neutral current.

- The source impedance doesn't influence the compensation characteristics.

- It is able to compensate voltage unbalances at the load terminals.

\section{Acknowledgement}

This work is within the project "Harmonic Distortion Compensation in Electrical Installations using Different Configurations of Active Power Filters." DPI2003-01336, financed by the CICYT (Ministerio de Ciencia y Tecnología, Spain).

\section{References}

[1] F. Z. Peng and D. J. Adams, "Harmonics sources and filtering approaches," in Proc. Industry Aplications Conference, October 1999, Vol, 1, pp. 448-455

[2] F. Z. Peng, H. Akagi, A. Nabae, "A novel harmonic power filter," in Proc. IEEE/PESC, April, 1988, pp. 1151-1159.

[3] J. W. Dixon, G. Venegas and L.A. Morán, "A series active power filter based on a sinusoidal current-controlled voltage-source inverter," IEEE Trans. Industrial Electronics. Vo, 44, no. 5, October 1997, pp. 612-620

[4] Z. Wang, Q. Wang, W. Yao and J. Liu, "A series active power filter adopting hybrid control approach," IEEE Trans. Power Electronics, vol. 16, no. 3, May 2001, pp. 301-310

[5] F. Z. Peng, H. Akagi, A. Nabae, "A new approach to harmonic compensation in power systems-a combined system of shunt passive and series active filters," IEEE Trans. Industry Applications. Vol, 26, no. 6, Nov/Dec 1990, pp. 983-990

[6] Y. S. Kim, J. S. Kim and S. H. Ko, "Three-phase threewire series active power filter, which compensates for harmonics and reactive power," IEE proc. Electr. Power Appl., Vol, 151, no. 3, May 2004, pp. 276-282

[7] H. Akagi, "Trends in active power line conditioners," IEEE Trans. Power Electronics, vol. 9, no. 3, May 1994, pp. 263-268

[8] A. Ghosh, A. K. Jindal, A. Joshi, "Design of a capacitorsupported dynamic voltage restorer (DVR) for unbalanced and distorted loads," IEEE Trans. Power delivery. Vo, 19, no.1, January 2004, pp. 405-413

[9] P. Salmerón, J. C. Montaño, J. R. Vázquez, J. Prieto, A. Pérez, "Compensation in Nonsinusoidal, Unbalanced Three-Phase Four-Wire Systems with Active Power Line Conditioner," IEEE Trans. Power Delivery, Vol. 19 (4), pp. 1968-1974, Oct. 2004. 